\title{
Prehistoric Sites near Flagstaff, Arizona*
}

GOME interesting inferences as to the geographical $\checkmark$ and economic factors involved in the development and distribution of prehistoric Pueblo culture in parts of northern Arizona are drawn by Dr. Harold S. Colton in a report on a survey of prehistoric sites in the neighbourhood of Flagstaff, which was carried out on behalf of the Museum of Northern Arizona in the course of ten summers between the years 1916 and 1930. It is the intention of the Museum ultimately to survey all sites in the northern area of the State, taking Flagstaff as a centre, but, for the present, attention is confined to those sites which lie to the east, between Flagstaff and the Hopi villages on the edge of the Painted Desert.

The area under investigation culminates in the San Francisco volcanic field, which is the second largest in the United States, and supports two hundred extinct cones, of which the highest form the massif known as San Francisco Peaks (12,700 ft.). From here the land slopes down into the valley of the Little Colorado River, rising again in terraces of vari-coloured cliffs, on the last of which stand the Hopi villages, to the Painted Desert.

The geological structure of the area is seen to have been an important factor in determining the distribution of prehistoric culture. Beneath the fields of volcanic ash and sand lie the Moencopi red sandstones and shales, the only rocks over a wide area which hold water. Wherever they have not been denuded, springs are found. Beneath them lie Kaibab limestone and Conconino limestone, both of which are waterless.

A further factor, which was discovered in 1930 only, is the recent activity of Sunset Crater in early Pueblo times. This was clearly a dominant event in the history and culture of the Pueblos. It took place somewhere between A.D. 600 and A.D. 850. A cover of black basaltic sand was then spread over the land for a radius of about twenty miles, in places near the crater to a depth of as much as two feet. It acted as a mulch, retaining the moisture and affecting the flow of the streams. It was eminently suited to the digging-stick type of cultivation affected by the Pueblo peoples. The population, which had hitherto congregated near the peaks, where a water supply was assured, is seen to have now spread densely over the area covered by the volcanic sand. They withdrew once more to the earlier sites near the peaks, or the shelter of the escarpment, when the prevailing winds in the course of time had removed the sand, except where anchored by vegetation, and

* "A Survey of Prehistoric Sites in the Region of Flagstaff, Arizona." By Harold S. Colton. Bulletin 104, Bureau of American Fthnology, had deposited it in the canyons, whence much of it has been carried away by the waters of the Little Colorado.

The operations of the survey with which $\mathrm{Dr}$. Colton deals in the present publication recorded 728 sites situated in the drainage areas of two tributaries of the Little Colorado, Walnut Creek and Deadman's Wash. The intervening watershed is omitted for future consideration.

Four culture horizons were recognised, which, in accordance with the nomenclature now adopted in Puebloan archæology, are classed as Basketmaker III, Pueblo I, Pueblo II and Pueblo III. The treering chronology worked out by Prof. Douglass on the basis of the growth of the trees used in Pueblo architecture, gives circa A.D. 900 for a few Pueblo II sites ; for Pueblo III, circa A.D. 1050-1300 ; and for Pueblo IV, A.D. 1300-1600. Applying this scheme to sites in the Flagstaff area gives the following as approximate dating for certain sites: Wupatki, 1087-1197; Citadel, 1192; Turkey Hills, 1203-1278; Ruin J, 1192. Pueblo IV and V are not represented. It was in late Pueblo II and early Pueblo III that the improvement in the conditions of agriculture and irrigation afforded by the black volcanic sand fostered the spread of a dense population over a wider area. The sites of these periods are thickly distributed between the Peaks and the Little Colorado. Black basaltic sand first enters into the tempering of material used in pottery in middle Pueblo II.

It is also to be noted that in Pueblo II and Pueblo III the pottery complexes in the Walnut Creek drainage and Deadman's Wash differ markedly and point to a complete dissociation of the two areas in culture. For this entire separation of the two tribes no reason is at present apparent.

No less than eight characteristic types of the Pueblo dwelling have been recorded in the area. They range through all stages from pit-houses to the Puebloan masonry multicellular dwelling. Some of the most interesting and characteristic dwellings are the cliff-shelters of Walnut Creek, south-east of Flagstaff, where the Kaibab limestone, overlying a precipitous wall of Conconino sandstone, weathers characteristically in a series of steps forming ledges with overhanging roofs. Here on each tier, rooms have been built in single rows, though in one or two places outer rooms have been added. Several of the dwellings have seven and eleven rooms; one is estimated doubtfully at thirty rooms. The greater number of these sites belong to Pueblo II and early Pueblo III.

A beginning has been made in the further explora. tion of the whole area by excavation.

\section{The Locust Problem}

$\mathrm{T}$ HE fourth report of the Committee on Locust Control of the Economic Advisory Council* contains a survey of investigations carried out in 1991, and a programme of work for 1932-33. Since the presentation of the previous report of the Committee, in 1930, invasions by the desert locust

* Economic Advisory Council : Committee on Locust Control. Fourth Report: Survey of Locust Investigations in 1931 and Programme of Work for 1932-33. (Cmd. 4124.) Pp. 43. (London; H.M. Stationery Office, 1932.) 18. net.

No. 3292, Vol. 130]
(Schistocera gregaria Forsk.) have continued in almost all the countries in Africa and western Asia that were previously affected. Further, a new and even more serious menace to agriculture in tropical Africa has presented itself in the appearance of great swarms of two other species of locusts, namely, the tropical migratory locust (Locusta migratorioides R. and F.) and the red locust (Nomadacris septemfasciata Serv.). 
Information gathered from official sources shows that the damage caused by locusts during the present outbreak (the period 1927-31) can be estimated, in round numbers, as exceoding $\mathfrak{1} 6,000,000$, while about $£ 1,000,000$ has been spent on control measures. The whole course of this outbreak clearly indicates how close is the dependence of the locust situation in any one territory on the general incidence of the pest over wide areas. This interdependence shows that it is almost futile to control locusts in a fow isolated districts. There is an urgent need for concentrating on investigations into the original breeding grounds of each locust species. The discovery of such areas would opon up the possibility of each species being dealt with under relatively localised conditions before it is ablo to spread and bocome diffused.

The events of the past two years all omphasise the urgency of discovering the specific factors that result in locust invasions in order that a far-reaching policy for the prevention, or at least the reduction of future outbreaks, may be devised. The Committee has drawn up a comprehensive programme of work that it recommends to bo carried out in 1932-33 and undertaken through the Imperial Institute of Entornology. At the headquartors of the Institute it is advised that the collection, study and analysis of availablo information on the problems involved should be continued and extended. The work also includes the task of transferring all records, both old and new, of locust migrations and breeding to maps covering dofined periods. Such maps should prove invaluable for tracing the courses of all known invasions and in serving as the basis for studies connected with them. Furthermore, as the Institute is acting as tho recognised international clearing. house for all information dealing with anti-locust investigation, in this way it is in a position to assist all countries directly affected by invasions. The collec. tion of specimens from swarms appearing in different lands, and at diverse times, is also being undertakon and their availability at the Institute will provide essential material for biometrical and other studies of the phase problem.

The field campaign, drawn up by the Committee, covers the investigation of the lifo-cycles of the locust species already mentioned; studies of their swarming and transitional phases; the correlation of locust activities with meteorological data and the testing of control measures. Theso aspects of the work will continue under the direction of the Chief Locust Investigator, Mr H. B. Johnston.

Tho co-operation of the governments of all countries affected by locust invasions is a matter of prime importance. It is now recognised that investi. gations of the character planned require to be international if the basic problems concerned are to be fully solved. The Committee acknowledges tho value of the co-operation alroady afforded by the French and Italian Governments, and by the administrations of British colonies and territories, but is anxious to develop mutual effort and the pooling of information on a much wider scale. Recommendations are consequently made that the Economic Advisory Council should invite the Secretary of State for Foreign Affairs to communicate copies of the present report with an expression of hope of co-operation, in the work now planned, of govern. ments that were not represented at the Rome conference on locust control in 1931 .

In the matter of finance, the recommendations of the Committec are on a very modest scale considering the importance of the schemes involved. The 1932-33 programme, as estimated, can be carried out at a cost of $£ 3,800$, of which $£ 395$ represents capital expendituro on tents, apparatus, etc., and $£ 3,405$ is recurrent oxpenditure mainly for salaries, wages and travelling charges. It is to be hoped that the campaign now taking shape will be allowed to develop so fully as possible, in view of the magnitude of the losses sustained through locust invasions in so many areas of the British Empire and indoed throughout the world.
A. D. ImMs.

\section{The Rubber Industry of Malaya}

A SERIES of memoranda with an introduction by Dr. H. A. Tempany which have recently been issued in Malaya deal with the position of the Rubber Resuarch Institute of Malaya and indicate that four distinct proposals for the future are before the Board. The retrenchment momorandum put forward by the executive committee estimates 350,000 dollars as tho sum on which the Institute's activities can be main. tained. This involves a reduction in expenditure of 183,000 dollars and at a special meeting of the Board of the Institute held on June 28, the recommendations of the executive committee were adopted with minor modifications.

The propasal of the Hon. B. J. R. Barton that the whole of the work of the Institute should be amalgamated with the Department of Agriculture was prompted by the belief that, while the retrenchment proposals did not go far enough to bring relief to subsoribers in any appreciable reduction in payment of cess, they would accentuate a feeling of discontent among tho staff of the Institute and that the organisation would not represent the best possible in the interests of the Industry. Mr. Barton stressed the advantages of the Department of Agriculture and while the retrenchment proposals may involve curtailing the advisory work, the activities of the
Institute can scarcely be maintained at more than a semblance of their present efficiency. The representatives of the Malaya Fstate Owners Association urged that the situation should be investigated by an indopendent body, but this proposal was also negatived.

The proposals adoptod by the Board, after accepting the view that 350,000 dollars represents the minimum upon which the activities of the Institute can be effectively muintained and the maximum which can be at present expected from the export cess levied on rubber, since the area of untapped rubber which escapes all contributions is expected to increase, provide for retrenchment by reduction in salaries, in the personnel and on allowances for cess, etc., on duty. In addition to a reduction of 5 per cent already imposed, a further reduction of 20 per cent on all salaries is now contemplated. With regard to personnel, the research servicos are graded in the order of importance, chemical, botanical, pathological, soils, field; and restriction of activity by reduction of personnel is advocated to fall with increasing incidence in the descending order shown above. On account of the increasing importance of latex, it is recommended that reduction in the chemical and pathological divisions where research on latex

No. 3292, VoL. 130] 